\title{
Ultrasound as a Sole Modality for Prenatal Diagnosis of Placenta Accreta Spectrum: Potentialities and Pitfalls
}

\author{
Anshika Gulati ${ }^{1}$ Rama Anand ${ }^{1}$ Kiran Aggarwal ${ }^{2}$ \\ ${ }^{1}$ Department of Radiology, Lady Hardinge Medical College, New \\ Delhi, India \\ 2 Department of Obstetrics and Gynecology, Lady Hardinge Medical \\ College, New Delhi, India \\ ${ }^{3}$ Department of Pathology, Lady Hardinge Medical College, New \\ Delhi, India
}

Indian J Radiol Imaging 2021;31:527-538.
Shilpi Agarwal ${ }^{3} \quad$ Shaili Tomer ${ }^{1}$
Address for correspondence Dr. Rama Anand, MD, Department of Radiology, Lady Hardinge Medical College, New Delhi 110001, India (e-mail: rama_home@yahoo.com).

\begin{abstract}
Keywords

- antepartum hemorrhage

- cesarean

- Doppler

- hysterectomy

- maternal mortality

- morbidly adherent placenta

- placenta accrete

- placenta increta

- placenta percreta

- placental lacunae

Background Placenta accreta spectrum (PAS) is a significant cause of maternal and neonatal mortality and morbidity. Its prevalence has been rising considerably, primarily due to the increasing rate of primary and repeat cesarean sections. Accurate prenatal identification of PAS allows optimal management because the timing of delivery, availability of blood products, and recruitment of skilled anesthesia, and surgical team can be arranged in advance.

Aims and Objectives This study aimed to (1) study the ultrasound and color Doppler features of PAS, (2) correlate imaging findings with clinical and per-operative/histopathological findings, and (3) evaluate the accuracy of ultrasound for the diagnosis of PAS in patients with previous cesarean section.

Materials and Methods This prospective study was conducted in radiology department of a tertiary care hospital. After screening 1,200 pregnant patients, 50 patients of placenta previa with period of gestation $\geq 24$ weeks and history of at least one prior cesarean section were included in the study. Following imaging features were evaluated: (1) gray scale covering intraplacental lacunae, disruption of uterovesical interface, myometrial thinning, loss of retroplacental clear space, and focal exophytic masses; and (2) color Doppler covering intraplacental lacunar flow, hypervascularity of uterine serosa-bladder wall interface, and perpendicular bridging vessels between placenta and myometrium.

Study Design Present study is a prospective one in a tertiary care hospital.

Results Of the 19 PAS cases, 18 were correctly diagnosed on ultrasonography (USG) and confirmed either by histopathological analysis of hysterectomy specimen or peroperatively due to difficulty in placental removal. PAS was correctly ruled out in 27 of 31 patients. The diagnostic accuracy of USG was $90 \%$. The sensitivity, specificity, positive, and negative predictive values were $94.7,87.1,81.8$, and $96.4 \%$, respectively.
\end{abstract}

DOI https://doi.org/ $10.1055 / \mathrm{s}-0041-1735864$. ISSN 0971-3026.
(C) 2021. Indian Radiological Association. All rights reserved.

This is an open access article published by Thieme under the terms of the Creative Commons Attribution-NonDerivative-NonCommercial-License, permitting copying and reproduction so long as the original work is given appropriate credit. Contents may not be used for commercial purposes, or adapted, remixed, transformed or built upon. (https://creativecommons.org/ licenses/by-nc-nd/4.0/)

Thieme Medical and Scientific Publishers Pvt. Ltd., A-12, 2nd Floor, Sector 2, Noida-201301 UP, India 
Conclusion Ultrasound is indispensable for the evaluation of pregnant patients. It is an important tool for diagnosing PAS, thereby making the operating team more cautious and better equipped for difficult surgery and critical postoperative care. It can be relied upon as the sole modality to accurately rule out PAS in negative patients, thereby obviating unnecessary psychological stress among patients due to possible hysterectomy.

\section{Introduction}

Hemorrhage is the leading cause of pregnancy-related maternal deaths, a vast majority of which is accounted for by placental disorders like placenta accreta spectrum (PAS). ${ }^{1}$

PAS, formerly known as morbidly adherent placenta, encompasses a spectrum of disorders ranging from abnormal adherence to complete penetration of placenta through the uterine wall. It is one of the most common indications for emergency peripartum hysterectomy ${ }^{2}$ with injury to the urinary bladder and other viscera as possible complications. The inability of the placenta to separate after delivery causes severe maternal morbidity due to retained placenta, septicemia, massive hemorrhage, and uterine rupture with frequent requirement for massive transfusions, intensive care unit (ICU) transfer, and prolonged hospital stay. ${ }^{3}$ PAS also increases neonatal mortality and morbidity due to preterm birth, low Apgar's score, respiratory distress syndrome, anemia, and others. ${ }^{4}$

Prior cesarean section (CS) and placenta previa (PP) are the two most important risk factors for PAS with further increased risk if both are present together. ${ }^{5}$ Related to the increasing and current all-time high rate of both primary and repeat cesarean deliveries, the frequency of PAS has now reached seemingly epidemic proportions. ${ }^{6}$ Its incidence was 1 in 533 deliveries in 2012. ${ }^{7}$

Ultrasonography (USG) is the quickest and safest method for the evaluation of placental disorders. It even helps in assessing fetal well-being and maturity by guiding the management, thereby improving perinatal prognosis and minimizing obstetric complications. ${ }^{6}$ Magnetic resonance imaging (MRI) also has been suggested as a tool to successfully diagnose PAS; however, its use is limited by cost, lack of portability, and long examination time.

The aim of this study was to investigate the accuracy of ultrasound and color Doppler in the diagnosis of PAS and also to optimize various imaging findings for fast and correct diagnosis.

\section{Materials and Methods}

Study design and patient selection: this prospective study was conducted for a period of 1.5 years from November 2015 to March 2017 in the Radiology Department, in collaboration with the Department of Obstetrics and Gynecology and Department of Pathology at Lady Hardinge Medical College in New Delhi, India. The Institutional Ethical Committee for Human Research approved this study.

A total of 1,200 pregnant patients presenting to the antenatal clinic or casualty were screened of whom 50 were enrolled in the study after applying the inclusion and exclusion criteria.

Pregnant patients with a period of gestation $\geq 24$ weeks having PP in present pregnancy and a history of at least one CS due to any cause were included in the study. Patients with not-low-lying placenta at an initial scan or on subsequent scans owing to placental migration were excluded.

\section{Study Methodology}

After taking informed written consent, detailed clinical history was taken and general physical and per-abdominal examinations were performed (-Fig.1). A detailed evaluation with USG and color Doppler was performed.

MRI findings were recorded for patients who were advised the same by the treating obstetrician.

The patients were managed according to the standard protocol and clinical outcomes were recorded. The standard of reference for the confirmation of the diagnosis of PAS was histopathological/per-operative findings.

Imaging technique and analysis: gray scale and color Doppler analyses were performed using a PHILIPS IU-22 machine with a 3- to 5-MHz convex sector transducer and 3- to 9-MHz linear array transducer. Acoustic gel was used for good skin transducer contact.

Each patient was called with a mildly distended bladder for a transabdominal scan. A routine obstetrics scan was first performed.

Placental tissue was studied both in longitudinal and transverse planes. The type of PP was classified as below: ${ }^{8}$

1. Major PP when the internal cervical os is partially or totally covered by the placenta.

2. Minor PP when the placental edge is within $2 \mathrm{~cm}$ but not covering any portion of the internal cervical os.

The following grayscale features of PAS were evaluated: intraplacental lacunae, irregularity/disruption of uterine serosa-bladder wall interface, myometrial thinning, loss of retroplacental clear zone, and focal exophytic masses. Intraplacental lacunae were assessed for number, shape, borders, and vascularity. ${ }^{9}$ Lacunar grading was done according to Finberg's classification. ${ }^{10}$ Segmental myometrial thinning of less than $1 \mathrm{~mm}$ was labeled as suggestive of PAS. ${ }^{11}$

Color Doppler evaluations were then performed. The region of interest (ROI) was selected on grayscale and the color Doppler mode was switched on. The mobile sector box was adjusted to lie exactly over the ROI. Two-dimensional (2D) gain was reduced for better depiction of color flow. Color Doppler, power Doppler, and pulsed Doppler 


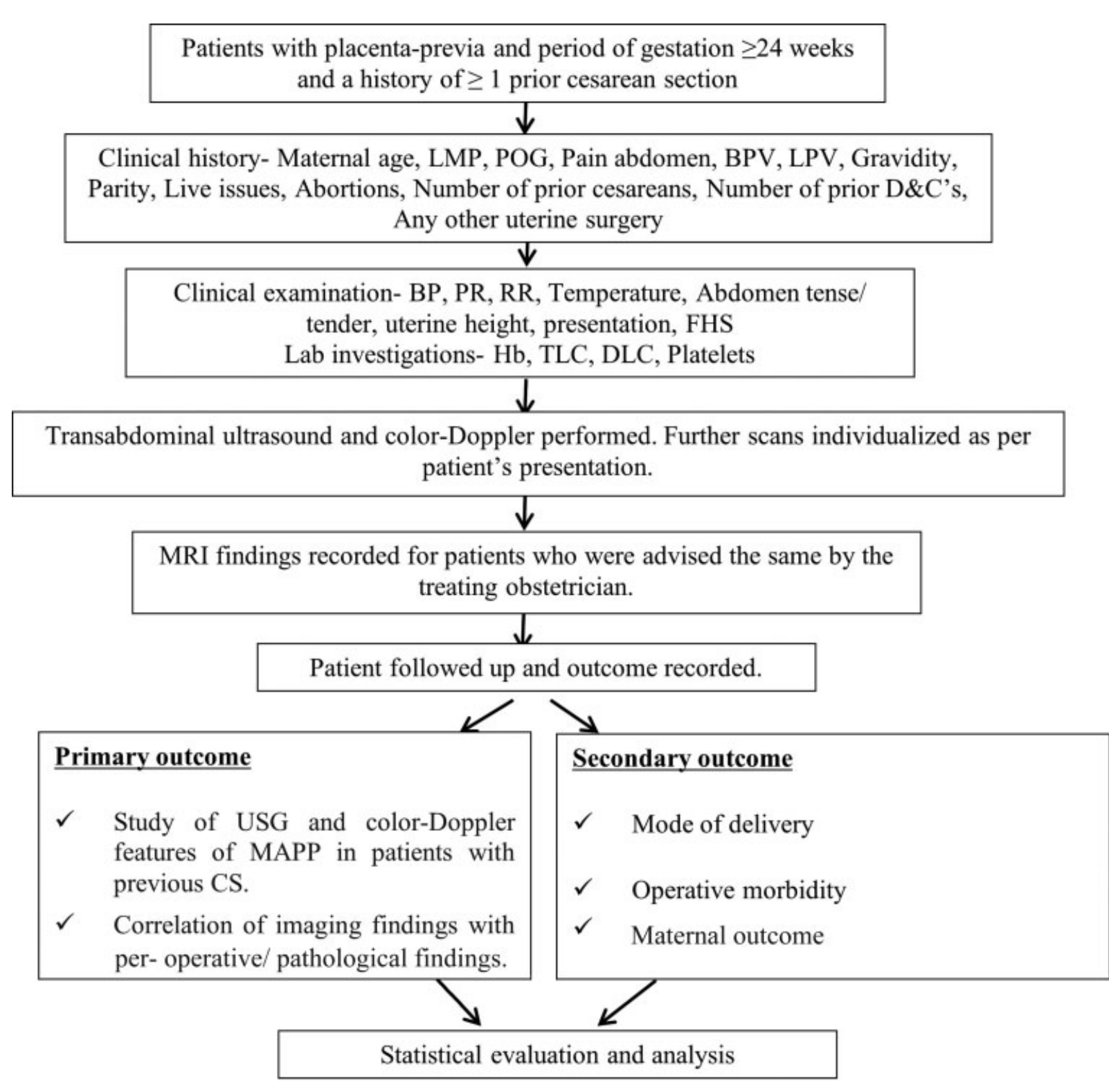

Fig. 1 Algorithm of methodology. CS, cesarean section; USG, ultrasonography. BPV, bleeding per vaginum; D\&C, dilation and curettage; FHS, fetal heart sound; LMP, last menstrual period; LPV, leaking per vaginum; MAPP, morbidly adherent placenta previa; POG, period of gestation.

parameters including wall filter, gate width, gain, and velocity scales were optimized for the detection of flow. The ALARA (as low as reasonably achievable) principle was implemented to ensure safe color Doppler imaging. The highest peak velocity of pulsatile venous flow within placental lacunae was obtained using angle correction and the resistance index of neovascularized arterial blood flow within the uterine serosa-posterior bladder wall boundary zone was definitely recorded in abnormal patients.

The following color Doppler features of PAS were recorded: sonolucent vascular lacunae with turbulent flow typified by high velocity (PSV $>15 \mathrm{~cm} / \mathrm{s}$ ) and low resistance waveform, hypervascularity of uterine serosa-bladder wall interface, low impedance flow in vascular branches coursing between the placenta and myometrium perpendicular to the long axis of the uterus, and markedly dilated vessels over the peripheral subplacental region (-Fig. 2). ${ }^{12}$
For patients presenting early in the third trimester, a follow-up scan was performed around 32 weeks to look for changes in placental localization, after which placental migration becomes unlikely. ${ }^{13}$ Further scans were individualized as per the patient's presentation. For patients presenting late in the third trimester, a single scan was performed.

Statistical evaluation: normally distributed variables were expressed as mean \pm standard deviation and continuous variables with skewed distribution as median (range). Qualitative data were expressed as number (percentage). Categorical variables were compared using the Chi-square test. A $p$-value of $\leq 0.05$ was considered to be statistically significant. Different diagnostic measures, such as sensitivity, specificity, and predictive values, were calculated. Receiver operating characteristic (ROC) curves were used to assess the diagnostic significance of intraplacental lacunae. Data were analyzed using the IBM SPSS Statistics software version 21.0. 


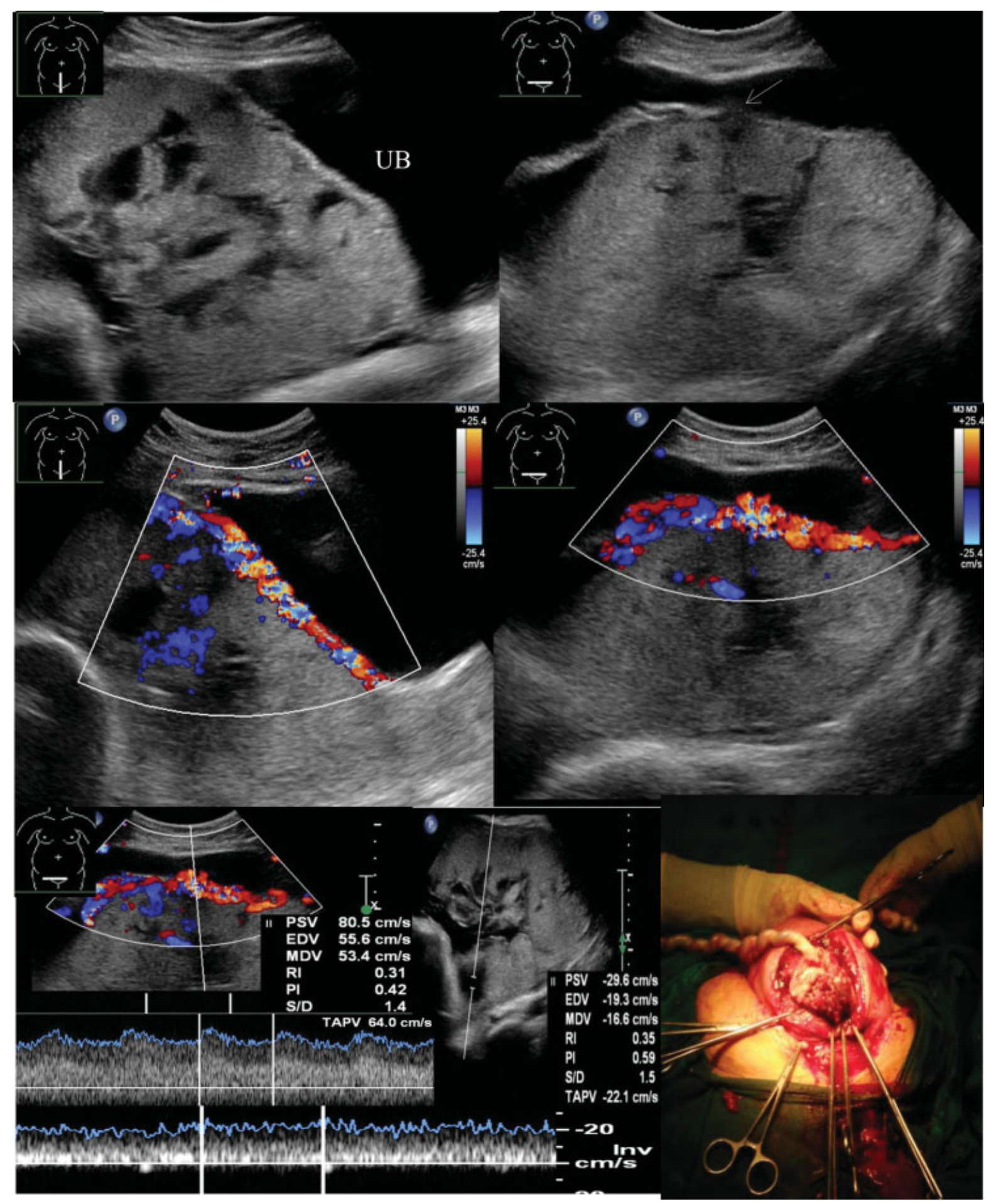

Fig. 2 A 28-year-old patient with previous two CS presented with APH. Transabdominal scan shows central placenta Previa. Heterogeneous placenta showing multiple large irregular-shaped lacunae with nonechogenic walls throughout its parenchyma (grade 3 ). Loss of clear space, marked myometrial thinning, and discontinuity (arrow) of echogenic bladder line with placental invasion into UB suggestive of placenta percreta. Color and spectral Doppler images show increased periuterine vascularity of low-resistance arterial flow. Lacunae show high-velocity venous flow. Intraoperative photograph shows thin and highly vascular LUS with densely adhered placental tissue. APH, antepartum hemorrhage; CS, cesarean section; UB, urinary bladder.

\section{Results}

Clinical characteristics are summarized in - Table 1. Seven PAS patients (36.8\%) did not have any clinical complaints. When symptomatic, the most common complaint was antepartum hemorrhage followed by abdominal pain. One unbooked patient presented at term with hematuria. On USG, a frank invasion of the urinary bladder with placental tissue was seen. Per-operative findings confirmed placenta percreta with bladder involvement which was managed by cesarean 
Table 1 Demographic characteristics, complications, management and clinical outcomes in patients with placenta accreta spectrum (PAS) and non-PAS

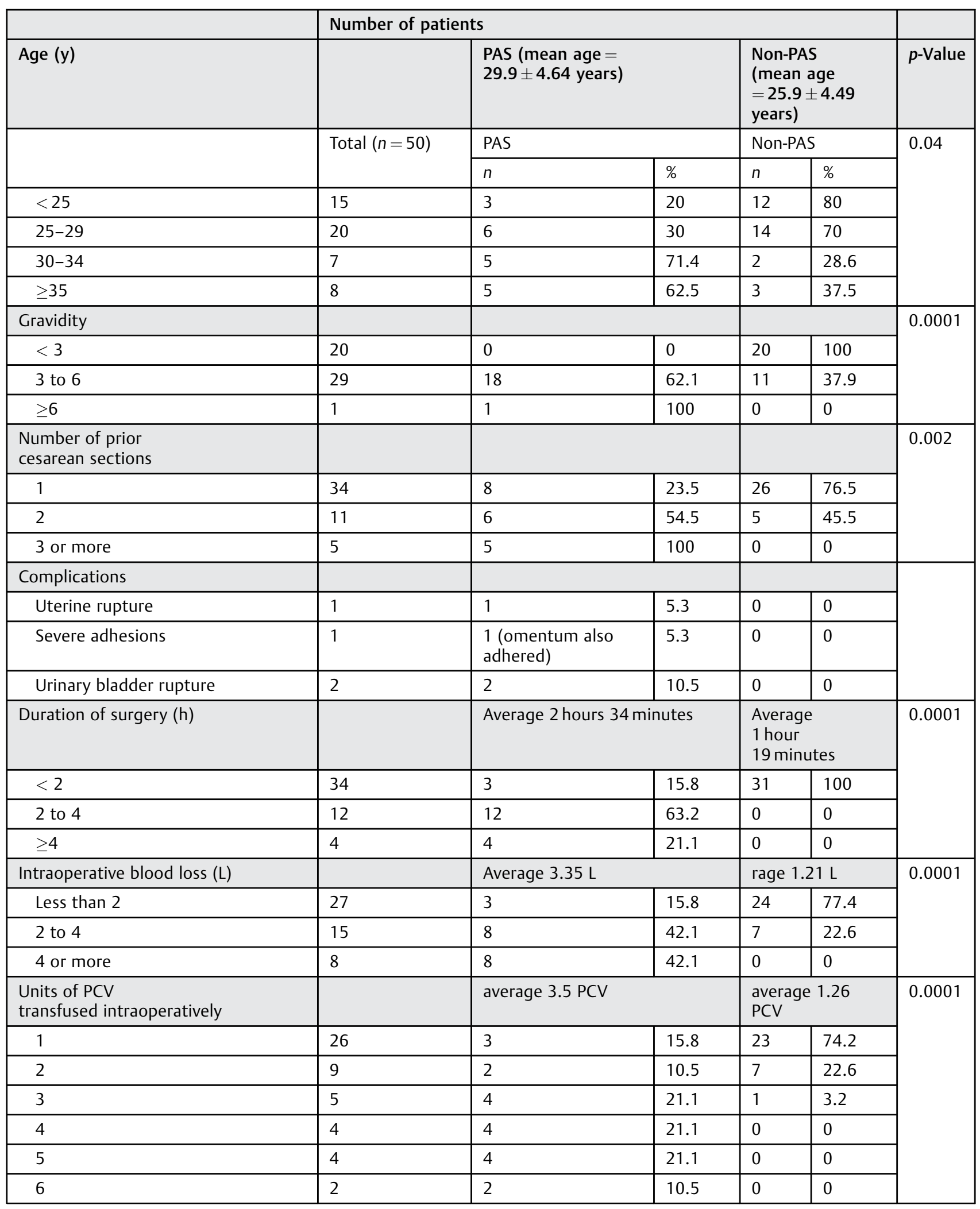


532 Ultrasound as a Sole Modality for Diagnosing Placenta Accreta Spectrum Gulati et al.

Table 1 (Continued)

\begin{tabular}{|c|c|c|c|c|c|c|}
\hline \multirow{3}{*}{$\begin{array}{l}\text { Age }(y) \\
\text { Operative management }\end{array}$} & \multicolumn{5}{|c|}{ Number of patients } & \multirow{3}{*}{$\begin{array}{l}p \text {-Value } \\
<0.05\end{array}$} \\
\hline & \multirow[b]{2}{*}{ Total $(n=50)$} & \multicolumn{2}{|c|}{$\begin{array}{l}\text { PAS (mean age }= \\
29.9 \pm 4.64 \text { years) }\end{array}$} & \multicolumn{2}{|c|}{$\begin{array}{l}\text { Non-PAS } \\
\text { (mean age } \\
=25.9 \pm 4.49 \\
\text { years) }\end{array}$} & \\
\hline & & $n$ & $\%$ & $n$ & $\%$ & \\
\hline Uterine artery ligation & 14 & 13 & 68.4 & 1 & 3.2 & \\
\hline Balloon tamponade & 2 & 1 & 5.3 & 1 & 3.2 & \\
\hline Iliac artery ligation & 14 & 13 & 68.4 & 1 & 3.2 & \\
\hline Cesarean hysterectomy & 16 & 16 & 84.2 & 0 & 0 & \\
\hline Total & 12 & 12 & 63.2 & 0 & 0 & \\
\hline Subtotal & 4 & 4 & 21.1 & 0 & 0 & \\
\hline \multicolumn{6}{|l|}{ Delivery of placenta } & \multirow[t]{5}{*}{$<0.05$} \\
\hline Spontaneous placental delivery & 28 & 0 & 0 & 28 & 90.3 & \\
\hline Uncomplicated manual removal & 3 & 0 & 0 & 3 & 9.7 & \\
\hline $\begin{array}{l}\text { Complicated manual removal: } \\
\text { removal in pieces }\end{array}$ & 3 & 3 & 15.8 & 0 & 0 & \\
\hline Hysterectomy & 16 & 16 & 84.2 & 0 & 0 & \\
\hline \multicolumn{6}{|l|}{ Clinical outcome } & \multirow[t]{3}{*}{$<0.05$} \\
\hline Maternal mortality & 1 & 1 & 5.3 & 0 & 0 & \\
\hline Perinatal mortality & 1 & 1 & 5.3 & 0 & 0 & \\
\hline
\end{tabular}

Abbreviation: PCV, packed cell volume.

hysterectomy and bladder repair ( - Fig. 3). Another unbooked patient was brought to casualty in shock. USG showed perforating placenta percreta and ascites with moving internal echoes. She was immediately taken up for surgery in view of fetal distress and active intraperitoneal bleeding. Hemoperitoneum of 1.5 to $2 \mathrm{~L}$ was drained per-operatively and delivery of fresh (intrauterine demise) IUD was followed by total hysterectomy; however, the patient did not survive.

Out of 50 patients, 19 were confirmed as PAS based on the histological analysis of the hysterectomy specimens of 16 patients (-Fig. 4) and in the remaining three patients, the diagnosis was confirmed per-operatively due to the difficulty in the manual removal of placenta that could be managed without hysterectomy. Of these 19 patients, 5 had placenta accreta vera, 2 had placenta increta, and 12 patients had placenta percreta. Also, 18 of 19 PAS cases were correctly diagnosed on USG and color-Doppler (true positive). In one case of PAS that was missed on USG, focal placental adherence was seen per-operatively; bleeding could not be controlled even after stepwise devascularization; hence, hysterectomy had to be done. Histopathology revealed placenta accreta vera (false negative). PAS was correctly ruled out by USG and color Doppler in 27 of 31 patients, thereby obviating unnecessary psychological stress among patients and their families due to possible hysterectomy (true negative). Of the four non-PAS patients who were erroneously diagnosed as PAS, one had multiple large intraplacental lacunae, another appeared to have multiple focal interruptions of retroplacental clear zone and two showed apparent hypervascularity of uterine serosa-bladder wall interface. However, the per-operative placental separation was complete in all four of them (false positive). The sensitivity, specificity, positive predictive value (PPV), and negative predictive value (NPV) of ultrasound and color Doppler in diagnosing PAS were 94.74, 87.1, 81.82, and $96.43 \%$, respectively (-Table 2 ) and positive likelihood ratio and negative likelihood ratio were $7.34,0.06$, respectively. Diagnostic accuracy was $90 \%$.

The most sensitive grayscale features for screening are myometrial thinning and loss of retroplacental clear space. With their high NPV of $96.6 \%$, they can be used to confidently rule out PAS in high-risk patients. If present, some features like irregularity/interruption of uterine serosa-bladder wall interface and focal exophytic masses are almost always predictive of PAS (100\% PPV; - Table 3).

A majority of non-PAS patients had grade 0 or grade 1 lacunae only. The patients of placenta accreta vera had a maximum of up to grade 2 , while two-third of patients with placenta percreta had grade-3 lacunae. The increase in the grade of intraplacental lacunae was significantly associated with the presence of PAS and also with the increase in the severity of PAS ( $p=0.0001$; - Table 4; -Fig. 5).

The intraplacental lacunae in most PAS patients had indistinct/nonechogenic borders, irregular shape, and turbulent flow, as compared with non-PAS patients whose lacunae had distinct echogenic borders and showed laminar flow (- Table 5).

There was a statistically significant increase in the amount of blood loss, intraoperative transfusion, and cesarean hysterectomy with increasing lacunar grade. Hence, the 


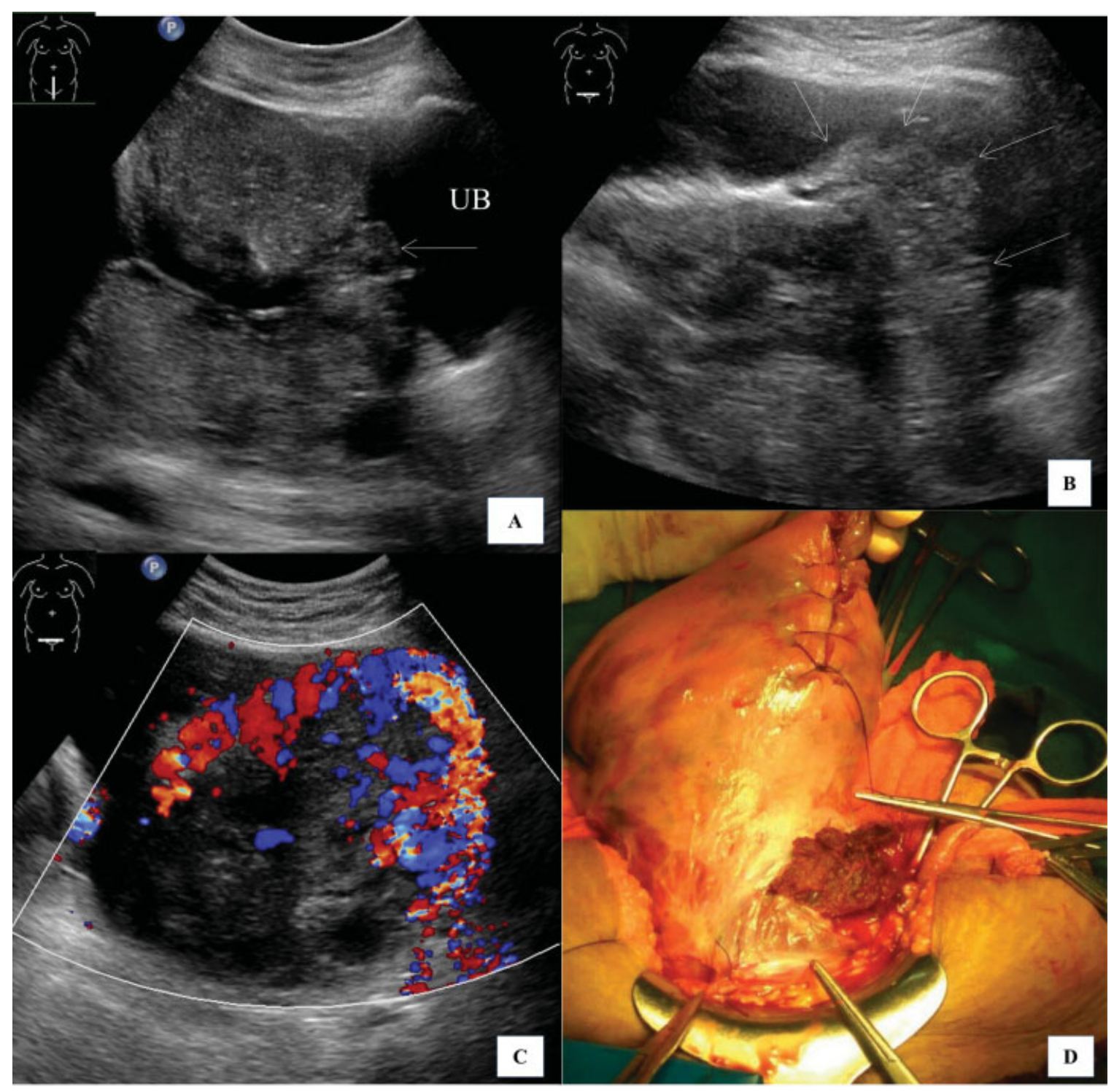

Fig. 3 Placenta percreta in a 29-year-old lady with two previous CS presented with APH. (A) TAS shows exophytic mass of same echogenicity as placenta invading into UB (arrow) with no identifiable myometrium, uterine serosa, or bladder wall in between. (B) Axial image at same level shows the exact site of invasion on the left of midline. (C) Color Doppler image of B shows extensive hypervascularity at uterovesical interface. (D) Intraoperative photograph shows the exophytic mass of placenta protruding outside the uterine serosa from the anterior wall of lower uterine segment. CS, cesarean section; TAS, transabdominal sonography; UB, urinary bladder.

lacunar grade can be used as a predictor of morbidity in patients with PAS (-Table 4).

Color Doppler features, like bridging vessels and uterovesical hypervascularity, further added to the diagnostic accuracy of USG with their high specificity of $93.5 \%$ and played a major role in ruling out PAS in high-risk patients with an NPV of 93.6\%. The most sensitive color Doppler features were intraplacental lacunar flow and perpendicular bridging vessels between the placenta and myometrium. The most specific color Doppler features were the hypervascularity of uterovesical interface and bridging vessels.

Management and clinical outcomes are summarized in -Table 1. There was one case of perinatal and maternal mortality due to PAS. Incidence of preterm delivery was higher in PAS patients which was done either in an emer- gency setting in view of APH or fetal distress or electively to prevent the risk of heavy bleeding and uterine rupture with increasing gestation. But this, in turn, predisposed the neonate to various complications due to prematurity while in most non-PAS patients, delivery could be safely planned after lung maturity was achieved. Regarding placental delivery, all non-PAS patients had their placenta removed completely with membranes, either by spontaneous separation or by manual removal. In three PAS patients, the placenta was removed in bits and pieces, followed by oozing of blood from the placental bed that could be controlled with hemostatic sutures and stepwise devascularization. Cesarean hysterectomy was required in 16 of 19 PAS patients in view of uncontrollable bleeding. Operative morbidity was significantly higher in PAS patients. The average duration of surgery and 


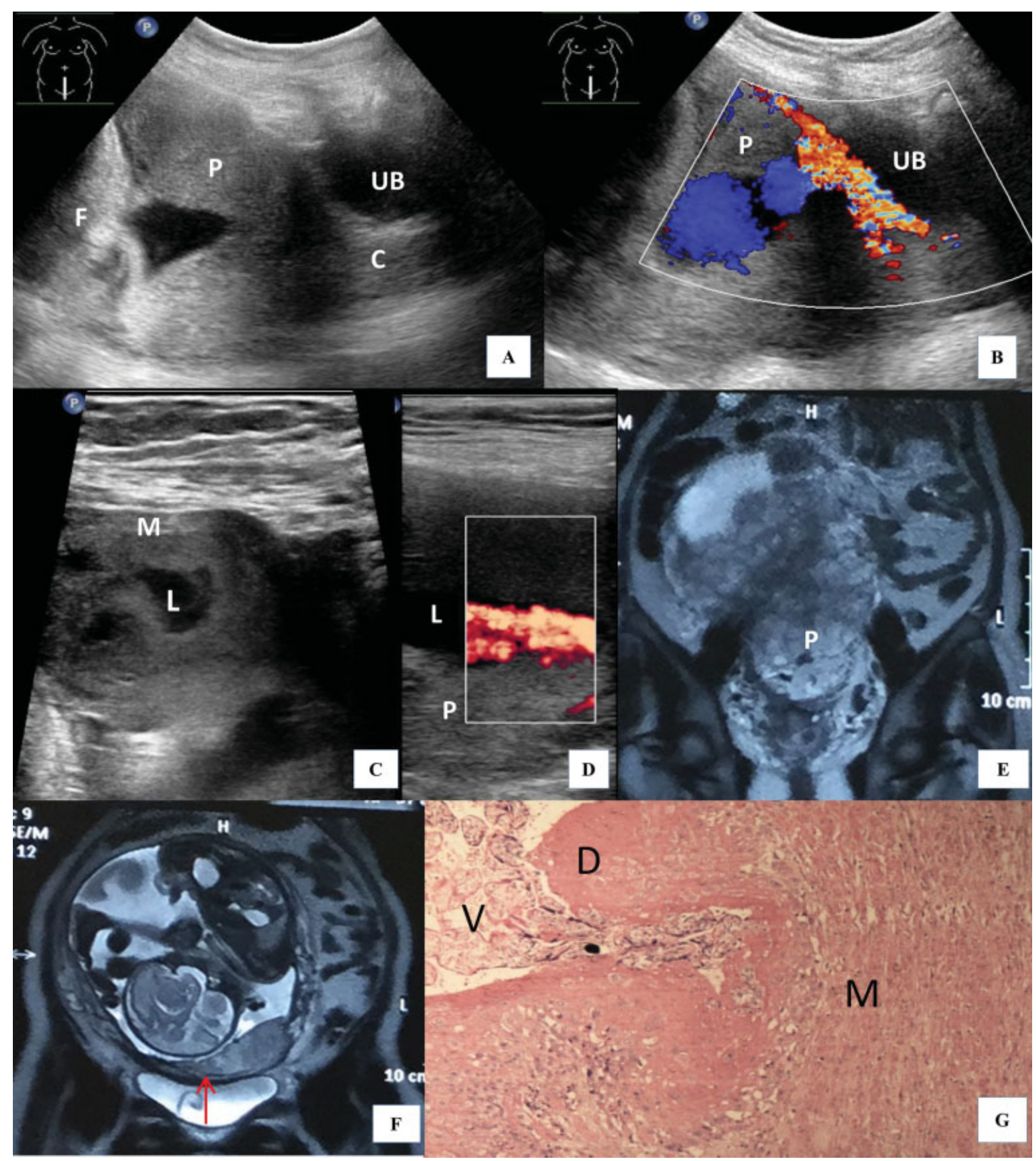

Fig. 4 Placenta accreta vera in a 38-year-old asymptomatic lady with prior 1 CS, 1 D and C, and 1 hysterotomy. (A) Central PP. Echogenic line of uterine serosa-bladder wall interface intact. (B) Subplacental hypervascularity, aberrant vessels crossing between the placental surfaces. (C, D) Loss of clear zone, myometrial thinning, and lacunae showing turbulent flow (E) Coronal T2W MRI shows heterogeneous placenta and multiple hypointense bands. (F) Coronal T2-W MRI shows the hypointense line of inner myometrium (arrow) becoming discontinuous on the left side. Outer myometrium and uterine serosa intact. (G) Hematoxylin and eosin stain $\times 100$ of hysterectomy specimen-placental villi $(\mathrm{V})$ invading decidua (D), reaching up to myometrium. CS, cesarean section; MRI, magnetic resonance imaging; T2-W, T2-weighted. C, cervix; D, decidua; F, fetus; L, placental lacunae; M, myometrium; P, placenta; UB, urinary bladder; V, placental villi.

intraoperative blood loss were more; devascularization procedures, like uterine/iliac artery ligation and balloon tamponade, were more frequently required. Two PAS patients required bladder repair. Omentum was also found adhered in one patient with placenta percreta. ICU transfer was required in $63.2 \%$ of PAS patients as compared with $19.4 \%$ non-PAS patients who required the same.

\section{Discussion}

The gold standard for the diagnosis of PAS are the per-operative and histopathological findings. The American College of Obstetricians and Gynecologists (ACOG) guidelines recommend that any placenta remaining in a contracting uterus for 2 hours or more after the birth of the baby without clinical 
Table 2 Diagnostic significance of ultrasound and color Doppler imaging

\begin{tabular}{|c|c|c|c|c|c|c|c|c|c|c|c|}
\hline \multirow{2}{*}{\multicolumn{4}{|c|}{ USG diagnosis }} & \multicolumn{6}{|c|}{ Final diagnosis } & \multirow{2}{*}{\multicolumn{2}{|c|}{ Total }} \\
\hline & & & & \multicolumn{3}{|c|}{ Non-PAS } & \multicolumn{3}{|l|}{ PAS } & & \\
\hline \multicolumn{4}{|c|}{ Non-PAS } & \multicolumn{3}{|c|}{$27(\mathrm{TN})$} & \multicolumn{3}{|l|}{$1(\mathrm{FN})$} & \multicolumn{2}{|l|}{28} \\
\hline \multicolumn{4}{|l|}{ PAS } & \multicolumn{3}{|c|}{4 (FP) } & \multicolumn{3}{|c|}{18 (TP) } & \multicolumn{2}{|l|}{22} \\
\hline \multicolumn{4}{|l|}{ Total } & \multicolumn{3}{|l|}{31} & \multicolumn{3}{|l|}{19} & \multicolumn{2}{|l|}{50} \\
\hline & TP & FP & $\mathrm{TN}$ & FN & PPV (\%) & NPV (\%) & Sn (\%) & Sp (\%) & $\begin{array}{l}\text { Positive } \\
\text { likelihood } \\
\text { ratio }\end{array}$ & $\begin{array}{l}\text { Negative } \\
\text { likelihood } \\
\text { ratio }\end{array}$ & $\begin{array}{l}\text { Diagnostic } \\
\text { accuracy (\%) }\end{array}$ \\
\hline USG & 18 & 4 & 27 & 1 & 81.82 & 96.43 & 94.74 & 87.10 & 7.34 & 0.06 & 90 \\
\hline
\end{tabular}

Abbreviations: FN, false negative; FP, false positive; NPV, negative predictive value; PAS, placenta accreta spectrum; PPV, positive predictive value; Sn, sensitivity; Sp, specificity; TN, true negative; TP, true positive; USG, ultrasonography.

Table 3 Diagnostic significance of different sonographic parameters

\begin{tabular}{|l|l|l|l|l|l|l|}
\hline Diagnostic criteria (gray scale) & $\begin{array}{l}\text { PAS } \\
(\boldsymbol{n}=\mathbf{1 9 )}\end{array}$ & $\begin{array}{l}\text { Non-PAS } \\
(\boldsymbol{n}=\mathbf{3 1})\end{array}$ & Sn (\%) & Sp (\%) & PPV (\%) & NPV (\%) \\
\hline Loss of clear space & 18 & 2 & 94.7 & 93.5 & 89.9 & 96.6 \\
\hline Myometrial thinning & 18 & 1 & 94.7 & 96.8 & 94.8 & 96.7 \\
\hline Intraplacental lacunae & 17 & 11 & 89.5 & 64.5 & 60.7 & 90.9 \\
\hline Focal exophytic masses & 10 & 0 & 52.6 & 100 & 100 & 77.5 \\
\hline Bladder line: irregularity/interruption & 9 & 0 & 47.4 & 100 & 100 & 75.7 \\
\hline Diagnostic criteria (color Doppler) & & & & & & \\
\hline Intraplacental lacunar flow & 17 & 5 & 89.5 & 83.9 & 77.3 & 92.9 \\
\hline $\begin{array}{l}\text { Perpendicular vessels between placenta } \\
\text { and myometrium (bridging vessels) }\end{array}$ & 17 & 2 & 89.5 & 93.5 & 89.4 & 93.6 \\
\hline Uterovesical/subplacental hypervascularity & 16 & 2 & 84.2 & 93.5 & 88.8 & 90.6 \\
\hline
\end{tabular}

Abbreviations: NPV, negative predictive value; PAS, placenta accreta spectrum; PPV, positive predictive value; Sn, sensitivity; Sp, specificity.

signs of separation must be considered morbidly adherent. ${ }^{7}$ Histopathologists define PAS as the partial or complete absence of decidua basalis, resulting in placental villi being attached to or invading the myometrium. It can be of three types. First, placenta accreta vera, the mildest form, refers to abnormal adherence without invasion into the myometrium. Second, placenta increta refers to myometrial invasion by placental villi. Third, placenta percreta refers to the penetration of placental villi through the entire myometrial thickness reaching up to or crossing the serosa. ${ }^{7}$ The invasion of chorionic villi into myometrial vascular spaces provokes a shift in placental blood supply from a spiral artery as found in normal placentation to supply from larger, deeper arteries, radial, or arcuate, in PAS. This leads to profound vascular alterations, such as the formation of placental lacunae and hypervascularization patterns under the placental bed. The more invasive the placentation, the more pronounced are the uteroplacental vascular changes. This confirms the value of color Doppler in screening PAS and the evaluation of the depth of villous myometrial invasion. A recent study by Shih et al showed the correlation of "rail sign" on color Doppler with deeper invasion of placental villi. It is seen as two parallel running vessels in bladder mucosa and uterovesical junction with perpendicular bridging vessels in between them. ${ }^{14}$
With the everincreasing number of CSs, the incidence of PAS has been rising at an alarming rate. In a study conducted by Shawky et al, there were 18 cases of PAS in a study population comprising 50 patients of PP with previous CS. ${ }^{9}$ In a study by Balcacer et al on 40 high-risk patients, 18 were positive for PAS. ${ }^{15}$ The frequency of PAS significantly increases with increasing age, gravidity, and parity. ${ }^{3}$ A history of previous CS increases the odds of having PAS by 8.7 times. ${ }^{16}$ According to ACOG, PAS is expected in $40 \%$ of patients with PP who have a history of previous two CSs. ${ }^{7}$ Major PP is associated with a five-fold increase in the risk of PAS as compared with minor PP or low-lying placenta. ${ }^{17}$ PAS is mostly seen associated with the placenta extending on the anterior uterine wall. ${ }^{18}$ However, the literature suggests that PAS may exist with the posterior placenta also. ${ }^{19}$

Most of the PAS cases are discovered only when manual removal of the placenta is required in the third stage of labor or even later when the patient presents with postpartum hemorrhage owing to incomplete placental separation. ${ }^{20}$ There are few case reports available in the literature of PAS presenting with frank hematuria owing to bladder involvement. ${ }^{21,22}$ There are few case reports of patients presenting with acute hypovolemic shock owing to placenta percreta. ${ }^{23}$ 
Table 4 Association of lacunar grade with the type of placental adherence and implications on management

\begin{tabular}{|c|c|c|c|c|c|c|c|c|c|c|}
\hline \multirow[t]{3}{*}{ Placental adherence } & \multicolumn{9}{|c|}{ Number of patients with respective lacunar grades } & \multirow{3}{*}{$\begin{array}{l}p \text {-Value } \\
<0.05\end{array}$} \\
\hline & \multirow[t]{2}{*}{ Total } & \multicolumn{2}{|c|}{ Grade 0} & \multicolumn{2}{|c|}{ Grade 1} & \multicolumn{2}{|c|}{ Grade 2} & \multicolumn{2}{|c|}{ Grade 3} & \\
\hline & & $n$ & $\%$ & $n$ & $\%$ & $n$ & $\%$ & $n$ & $\%$ & \\
\hline Non-PAS & 31 & 20 & 64.5 & 9 & 29 & 2 & 6.5 & 0 & - & \\
\hline Accreta vera & 5 & 1 & 20 & 1 & 20 & 3 & 60 & 0 & - & \\
\hline Increta & 2 & 0 & - & 1 & 50 & 1 & 50 & 0 & - & \\
\hline Percreta & 12 & 0 & - & 0 & - & 4 & 33.33 & 8 & 66.67 & \\
\hline Total & 50 & 21 & - & 11 & - & 10 & - & 8 & - & \\
\hline \multicolumn{11}{|l|}{ Need for hysterectomy } \\
\hline & & & & & & & & & & \multirow[t]{4}{*}{$<0.05$} \\
\hline Yes & 16 & 1 & 6.25 & 2 & 12.5 & 5 & 31.25 & 8 & 50 & \\
\hline No & 34 & 20 & 58.82 & 9 & 26.47 & 5 & 14.7 & 0 & - & \\
\hline Total & 50 & 21 & - & 11 & - & 10 & - & 8 & - & \\
\hline \multicolumn{11}{|c|}{ Units of PCV transfused } \\
\hline & & & & & & & & & & \multirow[t]{8}{*}{$<0.05$} \\
\hline 1 & 26 & 13 & 50 & 9 & 34.6 & 4 & 15.4 & 0 & - & \\
\hline 2 & 9 & 6 & 66.67 & 1 & 11.1 & 2 & 22.2 & 0 & - & \\
\hline 3 & 5 & 2 & 40 & 1 & 20 & 1 & 20 & 1 & 20 & \\
\hline 4 & 4 & 0 & - & 0 & - & 2 & - & 2 & 50 & \\
\hline 5 & 4 & 0 & - & 0 & - & 0 & - & 4 & 100 & \\
\hline 6 & 2 & 0 & - & 0 & - & 1 & - & 1 & 50 & \\
\hline Total & 50 & 21 & - & 11 & - & 10 & - & 8 & - & \\
\hline
\end{tabular}

Abbreviation: PAS, placenta accreta spectrum; PCV, packed cell volume.

The variable sensitivities and specificities of USG have been mentioned in the literature ranging from as low as 33\% by Lam et al to as high as $100 \%$ by Japaraj et al. ${ }^{24,25}$ Other studies evaluating the diagnostic accuracy of ultrasound showed varied findings. ${ }^{12,26}$

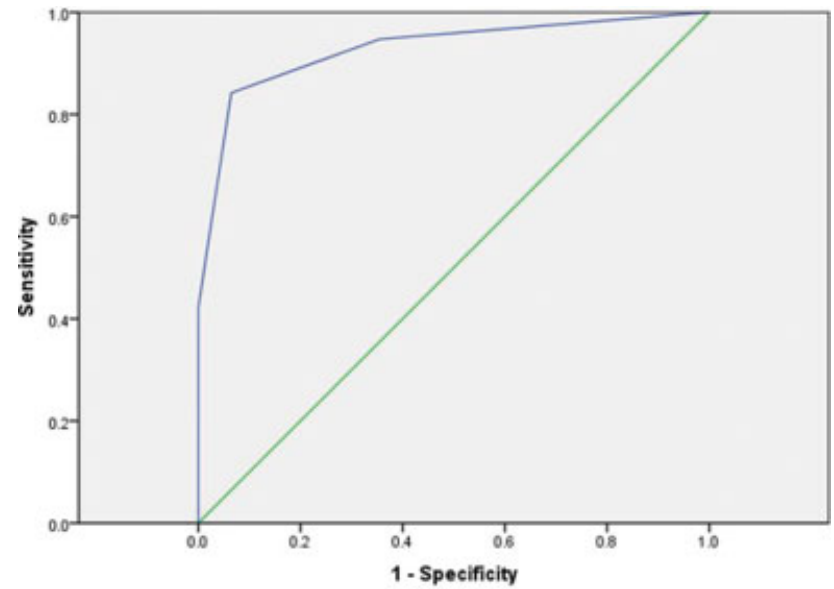

Fig. 5 The ROC curve for the diagnostic significance of intraplacental lacunae. Area under the ROC curve is $92.9 \%$ ( $95 \% \mathrm{Cl}: 0.79$ to 0.99 ) which reveals that the grading of intraplacental lacunae is sufficient for discriminating the positive and negative subjects. The best cut-off of grading is lacunar grade greater than 2 and at this point, sensitivity is $84.2 \%$ and specificity is $87.1 \%$. Cl, confidence interval; ROC, receiver operating characteristic.
Grayscale ultrasonographic findings suggestive of PAS are described hereinafter.

Vascular lacunae: irregular areas of low echogenicity larger than $1 \mathrm{~cm}^{2}$ in placental parenchyma forming "Swiss cheese" or "Moth-eaten appearance" (-Fig. 2). FinbergWilliams classified these lacunae as grade 0 when none are seen; grade $1+$ when one to three generally small lacunae are present; grade $2+$ when four to six larger or more irregular lacunae are present; grade $3+$ when there are many throughout the placenta, some appearing large and irregular in shape (10). Grade 2+ lacunae are strongly associated with PAS. ${ }^{27}$ According to the literature, the presence of placental lacunae is the most sensitive and highly predictive sonographic sign of PAS. ${ }^{18,25,27,28}$ We found that the higher the lacunar grade, the higher is the frequency and severity of PAS $(p=0.0001)$. Finberg-Williams also found similar associations. ${ }^{10}$ The lacunar grade is an important factor to predict peripartum complications in PAS. ${ }^{9,27}$

Interruption of echogenic bladder line: the normal interface between the myometrium and urinary bladder is smooth and echogenic. In PAS, myometrial thinning results in the irregularity or disruption of this vesicouterine interface. $^{10}$

Myometrial thinning: retroplacental myometrial thinning indicates the proximity of placental tissue to the uterine serosa or surrounding viscera. Segmental myometrial thinning of less than $1 \mathrm{~mm}$ is highly suggestive of PAS. ${ }^{11}$ 
Table 5 Evaluation of the imaging features of intraplacental lacunae and their association with placental adherence

\begin{tabular}{|c|c|c|c|c|c|}
\hline \multirow[t]{3}{*}{ Features of intraplacental lacunae } & \multicolumn{4}{|c|}{ Number of patients with intraplacental lacunae } & \multirow[t]{3}{*}{$p$-Value } \\
\hline & \multicolumn{2}{|c|}{ PAS } & \multicolumn{2}{|c|}{ Non-PAS } & \\
\hline & $n$ & $\%$ & $n$ & $\%$ & \\
\hline \multicolumn{5}{|l|}{ Grade } & \multirow[t]{5}{*}{0.0001} \\
\hline 0 & 1 & 5.3 & 20 & 64.5 & \\
\hline 1 & 2 & 10.5 & 9 & 29 & \\
\hline 2 & 8 & 42.1 & 2 & 6.5 & \\
\hline 3 & 8 & 42.1 & 0 & 0 & \\
\hline \multicolumn{5}{|l|}{ Shape } & \multirow[t]{4}{*}{0.02} \\
\hline Irregular & 14 & 77.8 & 6 & 54.4 & \\
\hline Linear & 2 & 11.1 & 2 & 18.2 & \\
\hline Round & 2 & 11.1 & 3 & 27.3 & \\
\hline \multicolumn{5}{|l|}{ Borders } & \multirow[t]{3}{*}{0.001} \\
\hline Echogenic (distinct) & 2 & 11.1 & 6 & 54.5 & \\
\hline Nonechogenic (indistinct) & 16 & 88.9 & 5 & 45.5 & \\
\hline \multicolumn{5}{|l|}{ Doppler study } & \multirow[t]{3}{*}{0.0001} \\
\hline Turbulent flow/tornado sign & 14 & 77.8 & 3 & 27.3 & \\
\hline Nonturbulent/laminar flow & 4 & 22.2 & 8 & 72.7 & \\
\hline
\end{tabular}

Abbreviation: PAS, placenta accreta spectrum.

Loss of retroplacental clear space: the absence of decidua basalis in PAS is seen sonographically as the loss of the hypoechoic area between the placenta and myometrium. ${ }^{10}$ A review of thee literature showed that the loss of clear space is the best criterion to rule out PAS with a high NPV of $97 \%$ and that if the echolucent area between the placenta and uterus is preserved, PAS is unlikely to occur. However, this criterion should not be used by itself to make a diagnosis, as it accounts for the majority of false positives. ${ }^{18}$ Riteau et al found that the loss of retroplacental clear space is the most sensitive parameter whereas McGahan et al found that the absence of this sonolucent line alone was not predictive of PAS and this hypoechoic line was even found to be absent in patients with normal pregnancies and they showed a sensitivity of only $7 \%{ }^{26,29}$ Shawky et al found that the absence of the retroplacental space had PPV of 59\%, indicating a low diagnostic value. ${ }^{9}$ Other studies have shown varied results. ${ }^{18,26}$

Presence of exophytic masses: the presence of extrauterine placental parenchyma is diagnostic of placenta percreta (-Fig. 3). ${ }^{10}$

Color Doppler imaging can improve the accuracy of the diagnosis of PAS since the depth of placental invasion into uterine myometrium can be determined. ${ }^{19}$ Normal placental vessels run parallel to the uterine long axis. In PAS, the vessels run through the myometrium perpendicular to the long axis of uterus. ${ }^{30}$ These findings of bridging vessels and uterovesical hypervascularity have a high specificity of $93.5 \%$ and also play a major role in ruling out PAS in high-risk patients with an NPV of 93.6\% ${ }^{25,26}$ Lacunae with a high-velocity turbulent flow (tornado-shaped flow of venous, arterial, or mixed blood) are more likely with PAS with PPV approaching $100 \% .^{9,28}$

\section{Strengths and Limitations}

The strength of our study and a major advantage over most other studies conducted on this subject to date was its prospective study design and thus the elimination of bias which may accompany the analysis of retrospectively evaluated cohort.

There were a few limitations in our study like the exclusion of patients without prior CS even if they had a history of other uterine surgeries, exclusion of patients without PP even if they had a history of classical CS; and the inherent limitations of USG in the evaluation of patients with obesity and advanced gestation.

\section{Conclusion}

Ultrasound is an excellent, simple, and safe technique for screening PAS in high-risk patients. It can be confidently relied on for accurately ruling out PAS in negative patients, thereby obviating unnecessary psychological stress (of possible hysterectomy) among patients and their families. Ultrasound is an important tool for diagnosing PAS, thereby making the operating team more cautious and better equipped for difficult surgery and critical postoperative care.

Financial Support and Sponsorship

None.

Conflicts of Interest

There are no conflicts of interest to declare. 


\section{References}

1 Berg CJ, Atrash HK, Koonin LM, Tucker M. Pregnancy-related mortality in the United States, 1987-1990. Obstet Gynecol 1996;88(02):161-167

2 Zorlu CG, Turan C, Işik AZ, Danişman N, Mungan T, Gökmen O. Emergency hysterectomy in modern obstetric practice. Changing clinical perspective in time. Acta Obstet Gynecol Scand 1998;77 (02):186-190

3 Metgud M, Koli P, Nilgar B, Mallapur M. Association of first birth cesarean delivery and placental abruption or previa at second birth. J South Asian Fed Obstet Gynecol 2010;2:23-26

4 Sheiner E, Shoham-Vardi I, Hallak M, Hershkowitz R, Katz M, Mazor M. Placenta previa: obstetric risk factors and pregnancy outcome. J Matern Fetal Med 2001;10(06):414-419

5 Gielchinsky Y, Rojansky N, Fasouliotis SJ, Ezra Y. Placenta accretasummary of 10 years: a survey of 310 cases. Placenta 2002;23 $(2,3): 210-214$

6 Wright JD, Silver RM, Bonanno C, et al. Practice patterns and knowledge of obstetricians and gynecologists regarding placenta accreta. J Matern Fetal Neonatal Med 2013;26(16):1602-1609

7 Committee on Obstetric Practice. Committee opinion no. 529: placenta accreta. Obstet Gynecol 2012;120(01):207-211

8 Shipp TD. Sonographic evaluation of the placenta. In: Rumack CM, Wilson SR, Charboneau JW, Levine D, eds. Diagnostic Ultrasound. 4th ed. Philadelphia, PA: Elsevier Mosby; 2011:1499-1504

9 Shawky M, AbouBieh E, Masood A. Gray scale and Doppler ultrasound in placenta accreta: optimization of ultrasound signs. Egypt J Radiol Nucl Med 2016;47(03):1111-1115

10 Finberg HJ, Williams JW. Placenta accreta: prospective sonographic diagnosis in patients with placenta previa and prior cesarean section. J Ultrasound Med 1992;11(07):333-343

11 Twickler DM, Lucas MJ, Balis AB, et al. Color flow mapping for myometrial invasion in women with a prior cesarean delivery. J Matern Fetal Med 2000;9(06):330-335

12 Chou MM, Ho ES, Lee YH. Prenatal diagnosis of placenta previa accreta by transabdominal color Doppler ultrasound. Ultrasound Obstet Gynecol 2000;15(01):28-35

13 Oppenheimer L, Holmes P, Simpson N, Dabrowski A. Diagnosis of low-lying placenta: can migration in the third trimester predict outcome? Ultrasound Obstet Gynecol 2001;18(02):100-102

14 Shih JC, Kang J, Tsai SJ, Lee JK, Liu KL, Huang KY. The "rail sign": an ultrasound finding in placenta accreta spectrum indicating deep villous invasion and adverse outcomes. Am J Obstet Gynecol 2021 (e-pub ahead of print). Doi: 10.1016/j.ajog.2021.03.018

15 Balcacer P, Pahade J, Spektor M, Staib L, Copel JA, McCarthy S. Magnetic resonance imaging and sonography in the diagnosis of placental invasion. J Ultrasound Med 2016;35(07):1445-1456
16 Hung TH, Shau WY, Hsieh CC, Chiu TH, Hsu JJ, Hsieh TT. Risk factors for placenta accreta. Obstet Gynecol 1999;93(04): 545-550

17 Bahar A, Abusham A, Eskandar M, Sobande A, Alsunaidi M. Risk factors and pregnancy outcome in different types of placenta previa. J Obstet Gynaecol Can 2009;31(02):126-131

18 Calì G, Giambanco L, Puccio G, Forlani F. Morbidly adherent placenta: evaluation of ultrasound diagnostic criteria and differentiation of placenta accreta from percreta. Ultrasound Obstet Gynecol 2013;41(04):406-412

19 Levine D, Hulka CA, Ludmir J, Li W, Edelman RR. Placenta accreta: evaluation with color Doppler US, power Doppler US, and MR imaging. Radiology 1997;205(03):773-776

20 Fox H. Placenta accreta, 1945-1969. Obstet Gynecol Surv 1972;27 (07):475-490

21 Shawish FM, Hammad FT, Kazim EM. Placenta percreta with bladder invasion. A plea for multidisciplinary approach. Saudi Med J 2007;28(01):139-141

22 Roux D, Horovitz J, Pariente JL, Lajus C, Le Guillou M, Dubecq JP. Placenta praevia percreta with bladder invasion: a case report [in French]. J Gynecol Obstet Biol Reprod (Paris) 1992;21(05): 579-580

23 Aho AJ, Pulkkinen MO, Vähä-Eskeli K. Acute urinary bladder tamponade with hypovolemic shock due to placenta percreta with bladder invasion. Case report. Scand J Urol Nephrol 1985;19 (02):157-159

24 Lam G, Kuller J, McMahon M. Use of magnetic resonance imaging and ultrasound in the antenatal diagnosis of placenta accreta. J Soc Gynecol Investig 2002;9(01):37-40

25 Japaraj RP, Mimin TS, Mukudan K. Antenatal diagnosis of placenta previa accreta in patients with previous cesarean scar. J Obstet Gynaecol Res 2007;33(04):431-437

26 Riteau AS, Tassin M, Chambon G, et al. Accuracy of ultrasonography and magnetic resonance imaging in the diagnosis of placenta accreta. PLoS One 2014;9(04):e94866

27 Yang JI, Lim YK, Kim HS, Chang KH, Lee JP, Ryu HS. Sonographic findings of placental lacunae and the prediction of adherent placenta in women with placenta previa totalis and prior Cesarean section. Ultrasound Obstet Gynecol 2006;28(02):178-182

28 Comstock CH, Love JJ Jr., Bronsteen RA, et al. Sonographic detection of placenta accreta in the second and third trimesters of pregnancy. Am J Obstet Gynecol 2004;190(04):1135-1140

29 McGahan JP, Phillips HE, Reid MH. The anechoic retroplacental area: a pitfall in diagnosis of placental-endometrial abnormalities during pregnancy. Radiology 1980;134(02):475-478

30 Khurana A. Placenta and transvaginal sonography. Donald School J Ultrasound Obstet Gynecol 2017;11(02):107-114 